\title{
PEER suite: A holistic approach to supporting inductive pedagogy implementation
}

\author{
William E. Lindsay, ${ }^{1}$ Valerie K. Otero, ${ }^{1}$ and Shelly N. Belleau ${ }^{1}$ \\ ${ }^{1}$ University of Colorado, School of Education, 249 UCB, Boulder, Colorado, 80309
}

\begin{abstract}
Our study reports on a field test examining the impact of the Physics through Evidence: Empowerment through Reasoning (PEER) curricular suite on high school students' conceptual physics understanding. The PEER suite holistically supports K-12 physics teachers' implementation of student-centered reform pedagogies that engage students in developing scientific principles from evidence. Components of the suite include NGSS-aligned curricular materials, targeted professional development with intentional fostering of professional communities, and assessment of multiple dimensions. Seven physics teachers field-tested PEER during the 2016-2017 school year and were compared to three physics teachers using a traditional approach. Findings indicate that PEER classes had higher pre/post gain scores in their conceptual understanding of physics than traditional classrooms. These preliminary results suggest that holistic approaches towards supporting physics education reform may be effective in facilitating shifts in students' conceptual understanding of physics.
\end{abstract}

\section{INTRODUCTION}

For over 100 years, physics education reformers have attempted to transform K-12 classrooms in order to increase student engagement with scientific practices and the inductive processes of science [1]. Students benefit from learning environments where they collect evidence, build models of phenomena, participate in scientific discourse, collaborate with peers, and have the authority to come to consensus on scientific ideas [2]. These experiences mirror processes of scientific induction, in which scientists come to consensus on widely-applicable principles from data. They also have the potential to decrease many of the participation gaps present in the physics workforce, as inductive teaching methods facilitate increased participation of students who are traditionally underserved in learning physics [3, 4].

Students who learn physics by doing, instead of solely learning about physics, have demonstrated greater pre/post gains scores on conceptual assessments of physics content knowledge than students in courses using didactic methods [5]. Case-study findings have also suggested that inductive pedagogy is correlated with a positive increase of underrepresented students' attitudes about using scientific practices [6], student empowerment to make-evidence based arguments [7], and more equitable learning outcomes for linguistically diverse students [8].

However, science education reformers have traditionally struggled to sustainably implement inductive pedagogies at scale [9]. Physics classrooms that empower students to participate in knowledge production have historically been an exception and not the norm despite available materials and knowledge [1]. Research on the implementation of the National Science Education Standards [10] found that the failure to foster large-scale change may be tied to a lack of multi-faceted support for teachers attempting reform [11]. Given the complex nature of educational settings, teachers need holistic support in designing inductive physics courses.

One current attempt at supporting K-12 physics teachers with transforming their classrooms is the Physics through
Evidence: Empowerment through Reasoning (PEER) curricular suite. Based off of design principles from the Physics and Everyday Thinking (PET) curriculum [12], PEER has been collaboratively developed over the past eight years by researchers, teachers, and graduate students at the University of Colorado Boulder. PEER employs a holistic model for supporting implementation of inductive physics pedagogy. The program has grown from an initial 2014-2015 classroom pilot to over 40 teachers and nine districts who are currently partnering with PEER.

To begin to investigate PEER's approach, our paper reviews research that ties PEER suite components and associated reform strategies to increased conceptual physics understanding for students. We then report on findings from a 2016-17 field test of PEER that addresses the following research question: What is the impact of teacher participation with the PEER curricular suite on course- and student-level gain scores in conceptual physics understanding, as compared to traditionally taught physics courses?

\section{PEER SUITE COMPONENTS}

\section{A. Transforming classrooms through laboratory-based curriculum resources}

Educational researchers claim that curricular materials can be leveraged to foster instructional change, because they provide a model for how to help students achieve desired learning outcomes [13]. In science education, this claim has been empirically supported by a recent randomized control trial, in which K-12 students who participated in a Next Generation Science Standards (NGSS) aligned curriculum outperformed students using a more traditional curriculum on assessments of conceptual understandings [14]. Similar results were also found in earlier studies funded by the National Science Foundation $[15,16]$.

In response to this research, PEER provides high school teachers with six physics units that span an entire school year. These units are designed for students to collaborate in small groups and as a whole class to use scientific practices 
to learn about physics content. Activities are based around physics phenomena, and students are carefully guided to build models of phenomena by following a learning cycle of Initial Ideas, Collecting and Interpreting Evidence, Summarizing Questions, and Scientists' Ideas Readings. For example, the PEER waves unit is centered on students building distinct but complimentary models of sound and light. PEER curricular materials thus serve as scaffolds for teachers designing inductive learning environments.

\section{B. Engaging teachers with targeted professional development and collaborative communities}

Equally important in supporting the implementation of inductive physics pedagogy is helping physics teachers gain a deep understanding of scientific practices and disciplinespecific instructional techniques that are necessary for transforming classrooms. Physics education researchers have theorized that many physics teachers have not had experiences inducing principles from data either in their own science programs or teacher preparation programs [17]. Relatedly, research on the implementation of the National Science Education Standards found that the further away a proposed reform intervention is from current classroom practice, the less likely it is for the intervention to be implemented successfully [18].

One strategy for overcoming these reform barriers is to immerse teachers in professional development (PD) experiences that help them induce both physics and pedagogical principles [19]. Accordingly, PEER PD engages teachers with model building activities to learn about evidence, inferences, mechanisms, and knowledge production as a dynamic process. These activities are designed to mirror the same inquiry approach that students engage with during PEER lessons, so as to help teachers understand the philosophy and pedagogy that underlie curricular materials. By using pedagogy parallel with inductive classroom practices, PEER PD helps teachers make sense of reform efforts and may increase chances that they will meaningfully shift their instruction.

As participation in the PEER suite grows, there has also been intentional fostering of a collaborative community where novice and veteran PEER teachers share resources and brainstorm solutions to common classroom issues. Recent research on ambitious instructional reform has highlighted the utility of such networks for teachers attempting to sustainably shift their instruction [20].

\section{Assessing Multiple Dimensions}

Noticeably absent from the publication of the NGSS, was a bank of assessments or performance tasks that teachers could easily adopt to assess their students' integrated understanding of scientific content and practices. Much has been written about the difficulty of writing and validating such tasks for classroom and research purposes [21], but the actual design of assessments has been mostly left to teachers.
Leaving the complex task of assessment development solely up to teachers serves as an active barrier to successful reform. The tendency for teachers to focus on content covered in assessments is well documented [22], resulting in science teachers privileging the teaching of easily assessed content over more difficult to evaluate scientific practices or deep conceptual understandings. To avoid this tendency, the PEER suite offers a bank of items to help teachers build assessments that encourage student engagement with multiple domains of knowledge. Though not available during the field-test reported on here, the PEER suite also offers 3dimensional performance tasks and engineering design challenges for each curricular unit.

In sum, the three suite components guide PEER's efforts in helping K-12 physics teachers meaningfully and sustainably transform their practice. As PEER's approach is grounded in education reform research that calls for more holistic supports in transforming classrooms [11], it may be more successful at supporting teachers implementing inductive physics pedagogy than solely providing teachers with curricular materials, PD, or assessments. In turn, successful implementation of inductive pedagogy may lead to better gains in students' conceptual physics understanding than students in classrooms using traditional methods, as has been demonstrated in previous science education reform efforts $[5,8,14,15,16]$. The remainder of this paper begins to test this hypothesis by reporting on student achievement data from a 2016-2017 field test of the PEER curricular suite.

\section{RESEARCH CONTEXT}

Our preliminary study investigated the impact of a yearlong field test of the PEER curricular suite on course- and student-level achievement outcomes, as compared to traditional courses. Our decision to use shifts in conceptual understanding as our major comparison indicator between PEER and traditional classrooms was informed by the large differences in pedagogy and valued learning outcomes between these two educational contexts. Teaching physics content was the most salient goal shared by both PEER and comparison teachers, so we used pre/post assessment methodology to assess differences between the two courses.

We collected data from the classrooms of seven PEER teachers in six schools, and three comparison teachers who used traditional teaching methods. Teachers implementing PEER taught in diverse district contexts, including two charter networks, three traditional public schools, and an arts-focused school. They also had a wide variety of experience teaching physics and working with the PEER project. To recruit comparison teachers, we sent an email to a list serve of local physics teachers offering a small financial compensation for participation. We accepted all volunteers who had appropriate district and student consent and who were teaching introductory physics. Researchers surveyed volunteer teachers to determine the physics pedagogy they used. All three volunteer teachers used traditional 
instructional methods; they mostly lectured as students took notes and then completed problem sets.

Pertinent demographic information for each teacher's school site is presented in Table 1, including the percentage of students who received free or reduced lunch (\%FRL), average PSAT score (PSAT), and the percentage of students who self-identify as people of color $(\% \mathrm{POC})$.

TABLE I. Demographic information for participating teachers' schools

\begin{tabular}{ccccc}
\hline \hline Teacher & Curriculum & \%FRL & PSAT & \%POC \\
\hline 1 & PEER & 54.3 & 902 & 71.3 \\
2 & PEER & 41.3 & 1044 & 40.1 \\
3 & PEER & 39.0 & 1015 & 25.4 \\
4 & PEER & 63.3 & 892 & 77.3 \\
5 and 6 & PEER & 79.4 & 1002 & 90.1 \\
7 & PEER & 38.3 & 926 & 32.2 \\
8 & Traditional & 32.2 & 1072 & 53.7 \\
9 & Traditional & 12.3 & 1136 & 28.7 \\
10 & Traditional & 42.5 & 927 & 40.3 \\
\hline \hline
\end{tabular}

As show in Table I, teachers 8 and 9 taught in schools with higher average PSAT scores and lower rates of students receiving free or reduced lunch than PEER schools.

\section{METHODOLOGY}

To measure gains in conceptual understanding, teachers administered the PEER conceptual exam at the beginning of their course (August) and the end of their course (May). The exam's content was drawn from a variety of conceptual items that have had content and face validity evidence gathered for their use in high school or college introductory physics courses, including items from the Force Concept Inventory [23] and the PET conceptual exam [12]. The conceptual test included 60 questions focused on topics covered in both PEER and comparison classrooms. Cronbach's alpha for these items equaled .91, indicating a high level of reliability.

We gathered data from 388 students and then omitted examinations that did not have a matching pre/post or when students did not give consent for research participation. 19 exams from PEER courses and 12 exams from traditional courses were removed because they were only pre/post and 14 exams from PEER courses and 11 exams from traditional courses were removed because students did not consent to participate in our study. In total, 201 students in PEER courses and 131 students in traditional courses were used in our analysis. Class sizes were approximately 30 students, and some teachers had multiple sections. We calculated gain scores by subtracting pre-test scores from post-test scores for each student and then averaged those scores for each teacher.

In addition, and to help control for other variables that may have affected student achievement results, researchers designed a linear regression model with post-test scores as the outcome measure, PEER classroom status as the predictor variable, and race, gender, and pre-test scores as control variables. This step shifted our unit of analysis from classrooms to individual students in an attempt to control for some of the differences between students in PEER courses and traditional courses. Dummy variables were produced for each student's self-reported race, gender, and inclusion in a PEER classroom. Dummy variables equal 1 if a student selfreported belonging in a category, and a 0 if they did not. As a reference category, we omitted the white racial dummy variable. We would have preferred to include other studentlevel variables like PSAT scores or final course grades into our model; however, our research team was not granted access to this data for individual students. Our linear regression model is represented below:

$$
\begin{aligned}
& \text { PostTest }_{\mathrm{i}}=\beta_{0}+\beta_{1}\left(\text { PEER }_{\mathrm{i}}\right)+\beta_{2}\left(\text { Female }_{\mathrm{i}}\right) \\
& +\beta_{3}\left(\text { Native }_{\mathrm{i}}\right)+\beta_{4}\left(\text { Hispanic }_{\mathrm{i}}\right)+\beta_{5}\left(\text { Black }_{\mathrm{i}}\right) \\
& +\beta_{6}\left(\text { Asian }_{\mathrm{i}}\right)+\beta_{7}\left(\text { PreTest }_{\mathrm{i}}\right)+\varepsilon_{\mathrm{i}}
\end{aligned}
$$

\section{V.FINDINGS}

Pre- and post-percentages and gain scores on the PEER conceptual exam for each participating teachers' courses are shown in Table II.

TABLE II. Mean percent PEER exam scores (SE)

\begin{tabular}{ccccc}
\hline \hline Teacher & N & Pre-Test & Post-Test & Gain Score \\
\hline 1 & 25 & $34.1(2.0)$ & $55.4(3.2)$ & $21.3(2.8)^{*}$ \\
2 & 18 & $33.8(2.0)$ & $59.3(4.0)$ & $25.5(2.6)^{*}$ \\
3 & 34 & $26.0(1.3)$ & $41.1(3.3)$ & $15.1(3.3)^{*}$ \\
4 & 40 & $29.7(1.8)$ & $54.8(2.8)$ & $25.0(2.3)^{*}$ \\
5 & 17 & $28.9(1.9)$ & $37.9(3.5)$ & $9.0(2.8)^{*}$ \\
6 & 43 & $20.6(1.6)$ & $44.2(2.0)$ & $23.6(2.1)^{*}$ \\
7 & 24 & $30.7(2.1)$ & $46.3(4.0)$ & $15.6(2.4)^{*}$ \\
PEER & 201 & $28.1(.8)$ & $48.4(1.3)$ & $20.3(1.0)^{*}$ \\
8 & 50 & $42.8(1.4)$ & $60.3(2.7)$ & $17.5(2.8)^{*}$ \\
9 & 54 & $35.2(1.3)$ & $40.7(1.7)$ & $5.5(1.8)^{*}$ \\
10 & 27 & $29.6(1.4)$ & $36.7(2.5)$ & $7.2(2.4)^{*}$ \\
Traditional & 131 & $36.9(.9)$ & $47.4(1.6)$ & $10.4(1.4)^{*}$ \\
*p-value $<0.05^{\text {p }}$ & & & \\
\hline \hline
\end{tabular}

On average, students in PEER courses had gain scores 9.9\% higher than students in traditional classes on an assessment of conceptual physics knowledge. This value was calculated by subtracting the mean gain score for students in PEER classes from the mean gain score for students in traditional courses. The difference in gain scores between students in PEER and traditional courses was statistically significant, with $\mathrm{t}(332)=5.7, \mathrm{p}<.001$.

As show in Table II, students in PEER courses had lower pre-test scores, on average, than students in comparison courses, but, after a year of participation with the PEER curricular suite, outperformed comparison students on the post-test assessment. Given the higher percentage of students with FRL status and lower PSAT scores than comparison courses, this finding suggests that participation with the 
PEER curricular suite may help students who have historically struggled in traditional physics courses.

Teacher 8's average gain score was much closer to the average PEER gain score than the other traditional courses. Teacher 8's students also had the highest average pre- and post-test percentages. We hypothesize that these results may be linked to teacher 8's courses being designed to prepare students for the Advanced Placement Physics 1 Exam.

The validity of these findings is also supported by a linear regression analysis that attempted to control for student-level variables present in our dataset that have historically influenced learning outcomes. Specifically, we included gender, race, and pre-test percentages as additional predictor variables. Our prediction model is represented below:

PostTest $_{i}=17.1+9.7\left(\right.$ PEER $\left._{\mathrm{i}}\right)+4.0\left(\right.$ Female $\left._{\mathrm{i}}\right)$

- 7.1 $\left(\right.$ Native $\left._{\mathrm{i}}\right)-4.6\left(\right.$ Hispanic $\left._{\mathrm{i}}\right)-7.1\left(\right.$ Black $\left._{\mathrm{i}}\right)$

$-7.4\left(\right.$ Asian $\left._{\mathrm{i}}\right)+.8\left(\right.$ PreTest $\left._{\mathrm{i}}\right)$

These results indicate that, on average, being in a PEER classroom versus a traditional classroom was associated with a positive $9.7 \%$ difference in post-test scores, after controlling for race, gender, and pre-test scores. This association was statistically significant, with $\mathrm{t}(332)=4.9$, $\mathrm{p}<.001$. The association is also similar to the $9.9 \%$ increase found by simply comparing shifts in pre/post scores of students in PEER and traditional courses. Finally, the model explained a significant proportion of variance in post-test scores, with $R^{2}=.30, F(1,332)=19.37, \mathrm{p}<.001$.

\section{VI.CONCLUSIONS}

Our paper has described one attempt at holistically supporting teachers in implementing inductive physics pedagogy. Preliminary findings from a year-long field test of this approach suggest that, on average, the courses of teachers involved with our project had higher gain scores in physics conceptual understanding than courses employing traditional methods. These results support our hypothesis that a holistic model in supporting teachers achieve pedagogical reform may lead to valued learning outcomes for students. This was true for courses in a wide variety of educational contexts, including public schools, charter networks, and an art-focused school. It was also true for courses serving students with lower conceptual background knowledge than students in comparison courses.

Due to the non-random nature of our sampling our study is descriptive and not causal; however, we have taken measures to control for cofounding variables that may have influenced outcome measures. Therefore, we are cautiously optimistic that an integrated approach of curriculum, PD, and assessment support may be effective at facilitating the implementation of student-centered pedagogies associated with valued learning outcomes. As participation in the PEER suite continues to grow, more research is needed to strengthen claims about the approach's effectiveness. For example, gathering teacher-level variables linked to student achievement from a larger sample of teachers may facilitate the usage of hierarchical linear models that help account for the nesting of students within teachers. In sum, we contend that a holistic approach to supporting teacher transformation may be more effective than one single intervention.

\section{ACKNOWLEDGEMENTS}

The writers wish to thank participating students and teachers, alongside NSF Grant \#937941 for project funding.
[1] V.K. Otero and D.E. Meltzer, Phys. Teach., 54, 9 (2016).

[2] National Research Council, A Framework for K-12 Science Education (National Academy Press, 2012).

[3] D.D. Minner, A.J. Levy and J. Century, J. Res. Sci. Teach., 47, 4 (2010).

[4] D.E. Meltzer and R.K. Thornton, Am. J. Phys., 80, 6 (2012).

[5] R.R. Hake, Am. J. Phys., 66, 1 (1988).

[6] S. Belleau, in Physics Education Research Conference Proceedings, 2012.

[7] S. Belleau, M.J Ross, and V.K. Otero, in Physics Education Research Conference Proceedings, 2011.

[8] S. Belleau and V.K. Otero in Physics Education Research Conference Proceedings, 2013.

[9] N.G. Songer, H.S. Lee and R. Kam, J. Res. Sci. Teach., 39, 2, (2002).

[10] National Research Council, National Science Education Standards (National Academy Press, 1996).

[11] R.D. Anderson and J.V. Helms, J. Res. Sci. Teach., 38, 1 (2001).
[12] F. Goldberg, V.K. Otero and S. Robinson, Am. J. Phys., 78, 12 (2010).

[13] D.L. Ball and D.K. Cohen, Ed. Res., 25, 9 (1996).

[14] C.J. Harris et al., J. Res. Sci. Teach., 52, 10 (2015).

[15] J.A. Shymansky, L.V. Hedges and G. Woodworth, J. Res. Sci. Teach, 27, 1 (1990).

[16] J.A. Shymansky, W.C. Kyle and J.M. Alport, J. Res. Sci. Teach., 20, 1 (1983).

[17] V.K. Otero and D.E. Meltzer, J. Col. Sci. Teach., 46, 3 (2017).

[18] P. Blumenfeld, P. Fishman, B.J. Krajcik, J. Marx and R.W. Soloway, Ed Psyc, 35, 3 (2000).

[19] S.M. Wilson, Science, 340, 6130 (2013).

[20] C.E. Coburn, J.L. Russell, J.H. Kaufman and M.K. Stein, Am. J. Ed., 119, 1 (2012).

[21] S.L. Pruitt, J. Sci. Teach. Ed., 25, 2 (2014).

[22] K. Menken, Bilingual. Res. J., 30, 2 (2006).

[23] D. Hestenes, M. Wells and G. Swackhamer, Phys. Teach., 30, 3 (1992). 